\title{
Ultrabiomicroscopy Anterior Segment Evaluation of Ocular Contusive Trauma Caused by Pressurized Bottled Drink Caps: A Case Report
}

\author{
Raffaele Antonio Esposito Alessandra Rosati Giuseppe Mannino \\ Gianluca Scuderi \\ Ophthalmology Unit, NESMOS Department, S. Andrea Hospital, Faculty of Medicine and \\ Psychology, University of Rome "La Sapienza", Rome, Italy
}

\section{Keywords}

Ultrabiomicroscopy $\cdot$ Contusive trauma $\cdot$ Cork $\cdot$ Pressurized bottled drinks

\begin{abstract}
We report the case of a patient presented to the emergency department because of a contusive trauma from a pressurized bottled drink cap. During the visit, the patient indicated that he had been hit in his left eye by a cork while he was opening a sparkling wine bottle. He underwent a total ophthalmology examination. He had an important reduction of visual acuity, corneal swelling, Descemet's folds, and hyphema. Therefore, we decided to perform ultrabiomicroscopy (UBM) of the anterior segment to study the endothelial damage and Descemet's membrane. UBM images confirmed the direct biomicroscopy, highlighting the damaged location.




\section{Introduction}

Unintentional eye injuries from bottles containing pressurized drinks are very common all over the word [1-5]. We have several ocular contusion registers that confirm the dimension of this phenomenon $[1,2]$.

Bottle caps may induce severe ocular damage due to the high-impact energy. A cork can reach a high velocity and thus energy, thanks to the high pressure inside bottles containing carbonated drinks. A $750 \mathrm{~mL}$ sparkling wine bottle contains 4,125 L of carbon dioxide that induces a pressure ( $6.2 \mathrm{bar}$ ) three times higher than that of a typical car tire. That pressure causes an ejection of $13 \mathrm{~m}$ for a cork of $30 \mathrm{~g}$, with a speed of $0.05 \mathrm{~s}$ that exceeds the blinking reflex which normally protects the eye from injuries [6].

The anterior segment is the part of the eye that is involved in a large number of cases, with the following morphological changes: corneal stroma edema, Descemet's folds, hyphema, iridodialysis, traumatic cataract, and vitreous prolapse [1,5]. Fortunately, anterior segment contusion has a good functional prognosis [5].

\section{Clinical Case}

We report the case of a 69-year-old male, who was hit by a cork while he was opening a sparkling wine bottle. The subject presented to Policlinico Umberto I First Aid, where he underwent medical examinations.

He had a BCVA (best corrected visual acuity) of 20/100 and ecchymosis of the superior and inferior eyelid. Slit-lamp examination showed conjunctival and pericorneal hyperemia, Descemet's folds, anterior chamber of normal dimension, cellular reaction (Tyndall 3+), a big clot from h6 to h10 hanging in the anterior chamber and partially obscuring the pupil, lens in situ.

The fundus was difficult to explore due to vitreous turbidity, even though the optic disc appeared pink with a sharp margin and Berlin's edema was detected. We decided to perform an ultrabiomicroscopy (UBM) (50MHz) evaluation to improve corneal damage. Thanks to that, we understood the importance of UMB exam as a diagnostic instrumental exam which supports biomicroscopy in anterior segment study. In fact, it is possible to identify where the damage is located in an accurate way: UBM images show us corneal stroma modifications as hyperechogenic areas and endothelial damage, with hyperechogenic spots under Descemet's membrane (Fig. 1, 2) [7, 8].

Eight years later, the patient presented to S. Andrea Hospital for a follow-up. He underwent UBM exam of the anterior segment that showed the remission of corneal changes (Fig. 3).

\section{Discussion}

UBM exam is a low-cost, manageable analysis that allows an immediate anterior segment evaluation by the healthcare operator. It is also important for patient follow-up and is used for a comparative analysis.

In conclusion, UBM exam is fundamental in the management and follow-up of contusive ocular traumas, such as those caused by the cork of a sparkling wine bottle. It could be considered an easy and fast exam in ophthalmologic First Aid. 


\section{Case Reports in Ophthalmology}

\section{Statement of Ethics}

The authors have no ethical conflicts to declare.

\section{Disclosure Statement}

The authors have no conflicts of interest to declare.

\section{References}

1 Viestenz A, Küchle M. [Eye contusions caused by a bottle cap. A retrospective study based on the Erlangen Ocular Contusion Register (EOCR)]. Ophthalmologe. 2002 Feb;99(2):105-8. German.

2 Kuhn F, Mester V, Berta A, Morris R. [Epidemiology of severe eye injuries. United States Eye Injury Registry (USEIR) and Hungarian Eye Injury Registry (HEIR)]. Ophthalmologe. 1998 May;95(5):332-43. German.

3 Zhu L, Lou D. Ocular injuries from pressurized bottled drinks in China. Injury. 2014;45(1):346-7.

4 Erdurman FC, Ceylan OM, Hürmeriç V, Pellumbi A, Durukan AH, Sobacı G. Ocular injuries caused by metal caps of carbonated mineral water bottles. Ulus Travma Acil Cerrahi Derg. 2013 May;19(3):256-60.

5 Cruciani F, Campagna O, Genzano M, Russo V. I traumi oculari contusivi e perforanti: studio epidemiologico. Oftalmol Soc. 2012;3:25-33.

6 Kuhn F, Mester V, Morris R, Dalma J. Serious eye injuries caused by bottles containing carbonated drinks. Br J Ophthalmol. 2004 Jan;88(1):69-71.

7 Ferrari G, Roszkowska A. Semeiotica della cornea, chapt. 15; 2007. p. 194-5.

8 Mannino G, Papale A, De Bella F. Biomicroscopia ad ultrasuoni in oftalmologia, chapt. 4; 2004. p. 80-3.

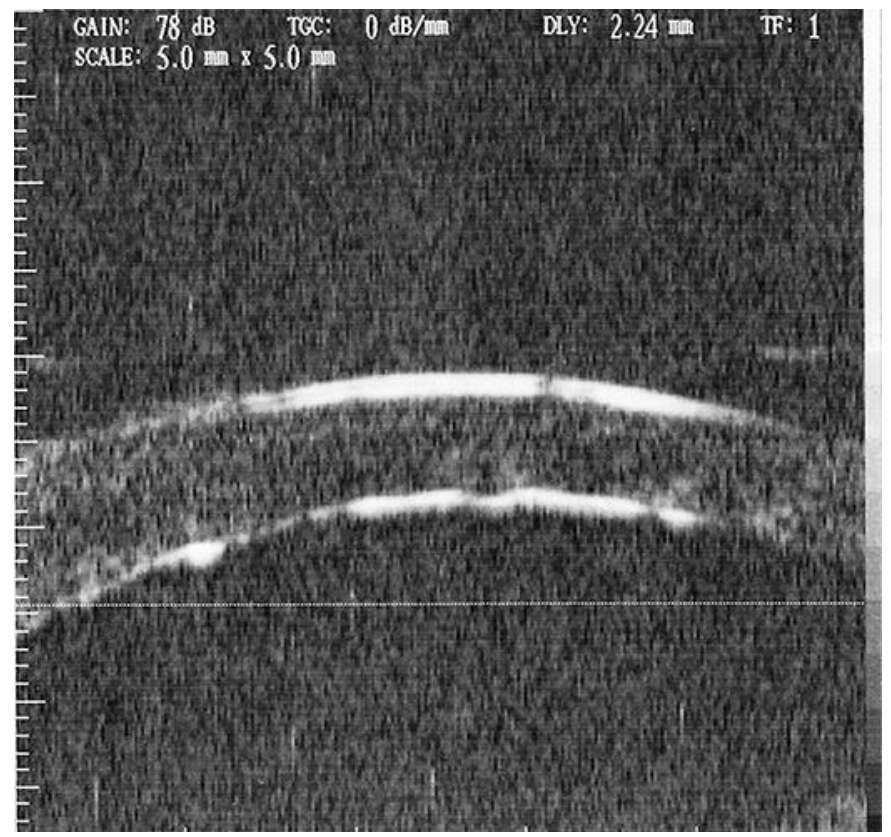

Fig. 1. UBM image that shows corneal modifications (stroma and endothelium). 


\section{Case Reports in Ophthalmology}

\begin{tabular}{l|l}
\hline Case Rep Ophthalmol 2018;9:365-368 \\
\hline DOI: 10.1159/000492107 & $\begin{array}{l}\text { @ } 2018 \text { The Author(s). Published by S. Karger AG, Basel } \\
\text { www.karger.com/cop }\end{array}$ \\
\hline
\end{tabular}

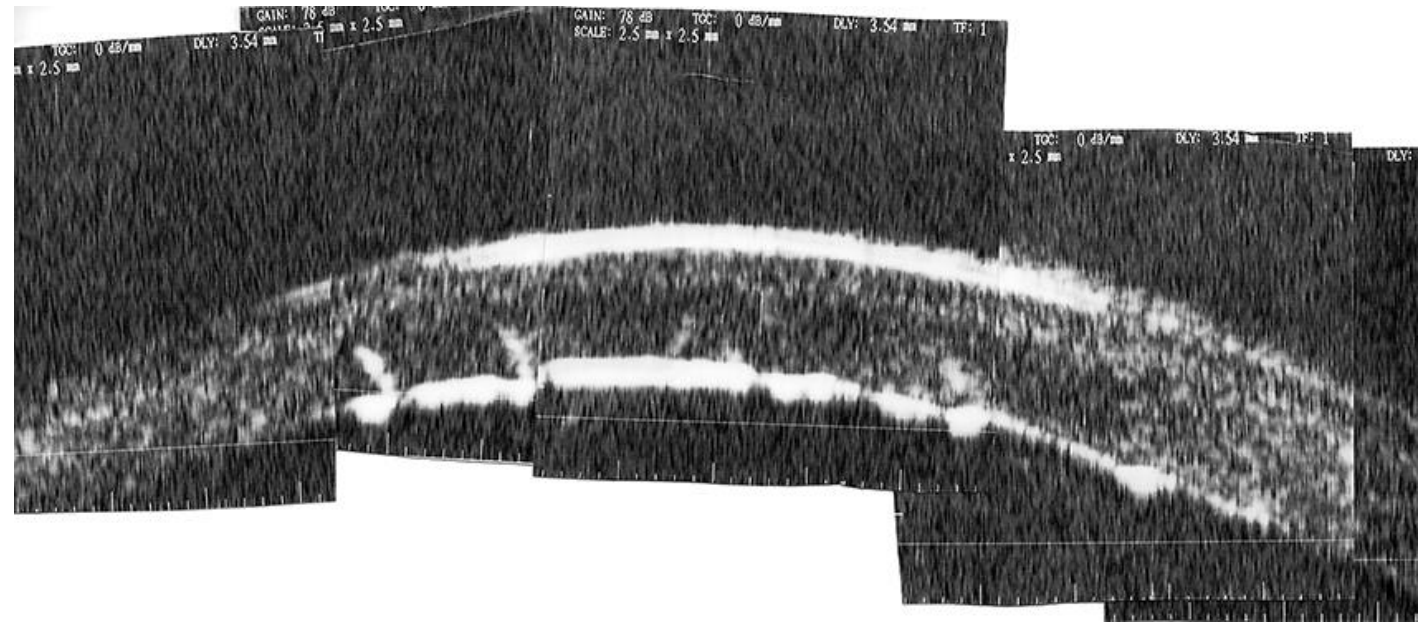

Fig. 2. Reconstruction and magnification of the UBM image.

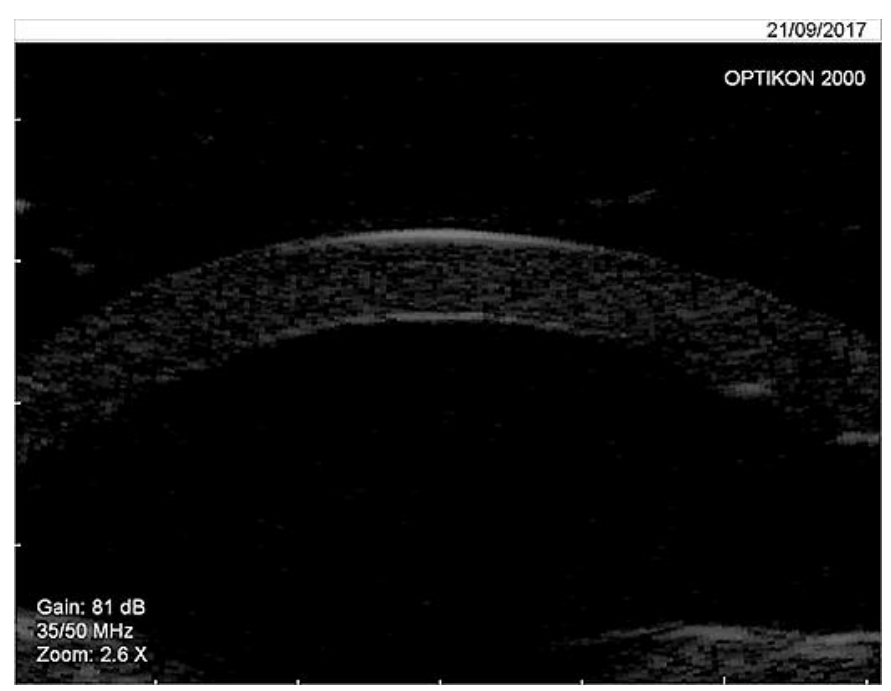

Fig. 3. UBM image that shows absence of corneal alteration. 